\title{
Elevated Neuronal Excitability Due to Modulation of the Voltage-Gated Sodium Channel Nav1.6 by $A \beta_{1-42}$
}

\author{
Xi Wang ${ }^{1+}$, Xiao-Gang Zhang ${ }^{1+}$, Ting-Ting Zhou ${ }^{2}, \mathrm{Na} \mathrm{Li}^{1}$, Chun-Yan Jang ${ }^{1}$, \\ Zhi-Cheng Xiao ${ }^{3}$, Quan-Hong $\mathrm{Ma}^{4}$ and Shao $\mathrm{Li}^{1 *}$ \\ ${ }^{1}$ Department of Physiology, Dalian Medical University, Dalian, China, ${ }^{2}$ Department of Neurology, the First Affiliated Hospital of \\ Dalian Medical University, Dalian, China, ${ }^{3}$ The Key Laboratory of Stem Cell and Regenerative Medicine, Kunming Medical \\ College, Institute of Molecular and Clinical Medicine, Kunming, China, ${ }^{4}$ Jiangsu Key Laboratory of Translational Research \\ and Therapy for Neuro-Psycho-Diseases, Institute of Neuroscience, Second Affiliated Hospital, Soochow University, Suzhou, \\ China
}

OPEN ACCESS

Edited by:

William Cho,

Queen Elizabeth Hospital, Hong Kong

Reviewed by:

Peng Lei,

Sichuan University, China M. Heather West Greenlee,

lowa State University, USA

*Correspondence:

Shao Li

lishao89@hotmail.com

${ }^{\dagger}$ These authors have contributed equally to this work.

Specialty section: This article was submitted to Neurodegeneration, a section of the journal

Frontiers in Neuroscience

Received: 21 December 2015

Accepted: 24 February 2016

Published: 09 March 2016

Citation

Wang $X$, Zhang $X-G$, Zhou T-T, Li N, Jang C-Y, Xiao Z-C, Ma Q-H and Li S (2016) Elevated Neuronal Excitability Due to Modulation of the Voltage-Gated Sodium Channel Nav1.6 by $A \beta_{1-42}$

Front. Neurosci. 10:94. doi: 10.3389/fnins.2016.00094
Aberrant increases in neuronal network excitability may contribute to the cognitive deficits in Alzheimer's disease (AD). However, the mechanisms underlying hyperexcitability are not fully understood. Such overexcitation of neuronal networks has been detected in the brains of APP/PS1 mice. In the present study, using current-clamp recording techniques, we observed that 12 days in vitro (DIV) primary cultured pyramidal neurons from P0 APP/PS1 mice exhibited a more prominent action potential burst and a lower threshold than WT littermates. Moreover, after treatment with $A \beta_{1-42}$ peptide, 12 DIV primary cultured neurons showed similar changes, to a greater degree than in controls. Voltage-clamp recordings revealed that the voltage-dependent sodium current density of neurons incubated with $A \beta_{1-42}$ was significantly increased, without change in the voltage-dependent sodium channel kinetic characteristics. Immunohistochemistry and western blot results showed that, after treatment with $A \beta_{1-42}$, expressions of $\mathrm{Nav}$ and Nav1.6 subtype increased in cultured neurons or APP/PS1 brains compared to control groups. The intrinsic neuronal hyperexcitability of APP/PS1 mice might thus be due to an increased expression of voltage-dependent sodium channels induced by $A \beta_{1-42}$. These results may illuminate the mechanism of aberrant neuronal networks in AD.

Keywords: Alzheimer's disease, beta-amyloid peptide, excitability, voltage-gated sodium channel, neurodegeneration

\section{INTRODUCTION}

Alzheimer's disease (AD) is the most frequent neurodegenerative disease and a common cause of dementia in elderly individuals. Various evidence suggests, that $\beta$-amyloid $(A \beta)$ peptides play a causal role in AD's pathogenesis, but the underlying mechanisms remain unclear (Palop and Mucke, 2010). In prodromal AD patients, functional MRI has revealed increased activities in neural networks, rather than loss of activity (Putcha et al., 2011). Other evidence supports the view, that $A \beta$-induced excitotoxicity could be critically involved in the pathogenesis of $\mathrm{AD}$ (Ong et al., 2013). In $\mathrm{A} \beta$-induced excitotoxicity, high levels of glutamate overexcite neurons and cause cell death (Choi, 1988; Olney et al., 1997). A $\beta$ also enhances the sensitivity of neuron to glutamate, which increases the activity of neuronal networks, resulting in excitatory potentials and $\mathrm{Ca}^{2+}$ influx (Brorson et al., 1995). However, these changes cannot 
explain patients with early $\mathrm{AD}$ frequently alternating between sober and confused, because synaptic disruption, or regeneration cannot repeatedly occur within such short time periods. This phenomenon is more likely due to the abnormal neural network excitability.

Voltage-gated sodium channels (Nav) play an essential role in excitable cells. They are necessary components required to generate and propagate action potentials (Goldin et al., 2000; Yu and Catterall, 2003; Catterall et al., 2005). The $260 \mathrm{kDa} \alpha$ subunit is the main component of the voltage-gated sodium channel. Nine $\alpha$ subtypes, named Nav1.1-Nav1.9, are expressed in excitable cells (Goldin et al., 2000; Ragsdale, 2008). Among them, the Nav1.1, Nav1.2, and Nav1.6 subtypes are expressed in the adult brain and regulate voltage-dependent sodium currents across the plasma membrane. Nav1.1 is primarily localized in the neuronal somata of GABAergic neurons (Yu et al., 2006; Ogiwara et al., 2007). Nav1.2 shows preferentially high expression in unmyelinated fibers (Ragsdale, 2008). The Nav1.6 subtype, encoded by the gene SCN8A, is conspicuously expressed at the nodes of Ranvier and axon initial segments (Trimmer and Rhodes, 2004). Unique features of Nav1.6 include its contribution to the persistent current, resurgent current, and repetitive neuronal firing.

Our previous results showed that Nav1.6 interacts with amyloid precursor protein (APP), which undergoes abnormal proteolytic processing to generate $\mathrm{A} \beta$ (Xu et al., 2014). APP also increases the surface expression of sodium channels through a $G_{0}$ protein-coupled JNK pathway (Liu et al., 2015). Due to this effect of APP, we hypothesized that the upregulatory effect of $A \beta$ on neuronal excitability might be partially based on modulating the expression of sodium channels. As we expected, in cultured cortical neurons, $A \beta_{1-42}$ increased the expression of sodium channels, particularly the Nav1.6 subtype. The increased voltage-dependent sodium current could decrease action potential threshold and increase the probability of action potential generation in response to synaptic excitation, thus increasing the excitability of the neuron.

\section{MATERIALS AND METHODS}

\section{Animals}

Newborn C57BL/6J mice were obtained from the Animal Center of Dalian Medical University. APP/PS1 transgenic mice were purchased from Jackson Laboratory (stock number 004462) and were maintained on a C57BL/6J background by crossing heterozygous transgenic mice with $\mathrm{C} 57 \mathrm{BL} / 6 \mathrm{~J}$ breeders. All experiments were conducted in accordance with the National Institutes of Health Guide for the Care and Use of Laboratory Animals. All efforts were made to minimize the number of animals used and their suffering.

\section{Preparation of $\mathbf{A} \boldsymbol{\beta}_{1-42}$}

Lyophilized $A \beta_{1-42}$ peptide (SIGMA, A9810) and reverse peptide $\mathrm{A} \beta_{42-1}$ (SIGMA, SCP0048) were diluted to $1 \mathrm{mg} / \mathrm{ml}$ using sterile PBS and incubated at $37^{\circ} \mathrm{C}, 220 \mathrm{rpm}$ for $48 \mathrm{~h}$ allowed to aggregate as described (Jones et al., 2013). For concrete forms of $\mathrm{A} \beta_{1-42}$ peptide, see Supplementary Figure S1. In a further set of experiments primary cultured neurons were incubated with $\mathrm{A} \beta_{1-42}(5.0 \mu \mathrm{M})$ or reverse peptide $\mathrm{A} \beta_{42-1}(5.0 \mu \mathrm{M})$ for $24 \mathrm{~h}$ at $37^{\circ} \mathrm{C}$.

\section{Cell Culture}

P0 (post-natal day 0-1) C57BL/6J mice or APP/PS1 mice and their littermates were sacrificed by $\mathrm{CO}_{2}$ inhalation and the cortices were rapidly dissected under sterile conditions in cold PBS. The tissue was digested with $0.125 \%$ trypsin-EDTA at $37^{\circ} \mathrm{C}$ for $30 \mathrm{~min}$. The trypsin solution was replaced with $2 \mathrm{ml}$ 10\% DMEM (DMEM with 10\% FBS, 1\% L-glutamine, and 1\% penicillin/streptomycin solution). The digested tissue was gently triturated by suction using a glass pipette flamed on the tip to avoid cellular damage. The cell suspension was filtered through a $74 \mu \mathrm{m}$ screen mesh, plated on poly-L-lysine-coated coverslips or 6/12-well-plates and incubated in a $37^{\circ} \mathrm{C}, 5 \% \mathrm{CO}_{2}$ incubator. After $2 \mathrm{~h}$, the medium was changed to Neurobasal (Gibco, 21103049) supplemented with $2 \%$ B27, $1 \%$ L-glutamine, and $1 \%$ penicillin/streptomycin. In accordance with the routine culture, the medium was changed every 2 days until use.

\section{MTT Assay}

Cell viability of neurons was determined by the MTT assay. Neurons were plated in 96 well-plates. $A \beta_{42-1}$ and $A \beta_{1-42}$ peptides were added to wells for $24 \mathrm{~h}$. After cell treatments the medium was removed and the cells were incubated with red free medium and MTT solution $(0.5 \mathrm{mg} / \mathrm{ml})$ for $4 \mathrm{~h}$ at $37^{\circ} \mathrm{C}$. Finally, the medium was removed and formazan particles were dissolved in DMSO. Cell viability, defined as the relative amount of MTT reduction was determined by spectrophotometry at $570 \mathrm{~nm}$.

\section{Electrophysiological Recordings}

Electrophysiological measurements were performed on pyramidal cells. Action potentials or sodium currents were recorded at room temperature using whole-cell patch-clampings. The extracellular solution contained the following (in $\mathrm{mM}$ ): $\mathrm{NaCl} 150, \mathrm{KCl} 5, \mathrm{MgCl}_{2}$ 1.1, $\mathrm{CaCl}_{2}$ 2.6, HEPES 10, glucose $10, \mathrm{pH}$ adjusted to 7.4 with $\mathrm{NaOH}$. Patch pipettes were made from borosilicate glass capillaries $(1.5 \mathrm{~mm}$ outer diameter, $0.8 \mathrm{~mm}$ inner diameter) using a micropipette puller (Narishige, PP 830, Japan). Pipette resistance ranged from 3 to $5 \mathrm{M} \Omega$. Stimulation and data acquisition were performed using the EPC-10 patch-clamp amplifier and Pulse program (HEKA Electronik, Germany). Membrane currents were filtered at $2 \mathrm{kHz}$ and digitized at $10 \mathrm{kHz}$.

Action potentials recordings were made using the currentclamp mode. The intracellular solution contained the following (in $\mathrm{mM}$ ): $\mathrm{KCl} 65, \mathrm{KOH} 5.0, \mathrm{KF} 80$, HEPES 10, EGTA 10, $\mathrm{Na}_{2}$ ATP 2, $\mathrm{pH}$ adjusted to 7.2 with $\mathrm{KOH}$. Cells were held at $-70 \mathrm{mV}$, then peak amplitude ( $80 \mathrm{pA}, 10 \mathrm{~ms})$, threshold ( $80 \mathrm{pA}, 10 \mathrm{~ms})$, and action potential firing $(200 \mathrm{pA}, 500 \mathrm{~ms})$ were recorded and measured.

Sodium currents were recorded using the voltage-clamp mode. The intracellular solution contained the following (in $\mathrm{mM}$ ): $\mathrm{CsCl}$ 140, $\mathrm{MgCl}_{2}$ 2, $\mathrm{Na}_{2}$ ATP 2, EGTA 10, HEPES 20, $\mathrm{pH}$ adjusted to 7.2 with Tris- $\mathrm{HCl}$. Cells were held at $-70 \mathrm{mV}$ and stepped to a range of potentials $(-60$ to $+60 \mathrm{mV}$ in $10 \mathrm{mV}$ 
increments) for $12 \mathrm{~ms}$ each. Peak inward currents (I) were plotted as a function of depolarizing potential to generate I-V curves. Activation curves were obtained by converting current (I) to conductance $(\mathrm{G})$ at each voltage $(\mathrm{V})$ using the equation $\mathrm{G}=$ $\mathrm{I} /\left(\mathrm{V}-\mathrm{V}_{\text {rev }}\right)$, where $\mathrm{V}_{\text {rev }}$ is the reversal potential, which was determined for each cell individually. Activation curves were then fit with the Boltzmann function in the form of $\mathrm{G} / \mathrm{G}_{\max }=$ $1 /\left\{1+\exp \left[\left(V_{1 / 2}-V\right) / \kappa\right]\right\}$, where $G_{\max }$ is the maximal sodium conductance, $\mathrm{V}_{1 / 2}$ is the half-maximal activation potential, $\mathrm{V}$ is the test potential, and $\kappa$ is the slope factor. Steady-state fast inactivation was achieved with a series of $500 \mathrm{~ms}$ prepulses $(-120$ to $-10 \mathrm{mV}$ in $10 \mathrm{mV}$ increments), and the remaining available channels were activated by a $12 \mathrm{~ms}$ test pulse to $0 \mathrm{mV}$. Peak inward currents obtained from steady-state fast-inactivation protocols were normalized to the maximal peak current $\left(I_{\max }\right)$ and fit with Boltzmann functions: $\mathrm{I} / \mathrm{I}_{\max }=1 /\{1+\exp [(\mathrm{V}-$ $\left.\left.\left.\mathrm{V}_{1 / 2}\right) / \kappa\right]\right\}$, where $\mathrm{V}$ represents the inactivating prepulse potential, and $V_{1 / 2}$ represents the mid-point of inactivation curve.

\section{Data Analysis}

Data were analyzed using Pulsefit 8.6 and Origin 7.5, and presented as means \pm SEM. The Kruskal-Wallis non-parametric test was used to analyze current density data. One-way ANOVA was used to assess the statistical significance of changes in characteristics of channel activation and inactivation. Statistical comparisons were performed by Student's $t$-test.

\section{Western Blot}

All cells were lysed in RIPA buffer (with 1\% PMSF), and total protein concentrations were determined with a BCA Protein Assay Kit (TransGen). Total protein (10-20 mg) for each sample was loaded into precast $8 \%$ SDS-PAGE gels and run with running buffer. Gels were transferred onto PVDF membranes (Millipore). Antigen-specific primary antibodies (Pan sodium channel, Chemicon-AB5210; Nav1.6, Chemicon-AB5580 and Abcamab65166; $\beta$-tubulin, Abcam-ab6046; $\beta$-actin, Abcam-ab6276) were incubated overnight at $4{ }^{\circ} \mathrm{C}$ and detected with speciesspecific horseradish-peroxidase-labeled secondary antibodies. An ECL Western Blotting Detection kit (TIANGEN) was used to obtain a chemiluminescence signal, which was detected using Gel Imaging System (Bio-Rad). Band quantification was performed using a Gel-Pro software. Bands of interest were normalized to actin- or tubulin- for a loading control.

\section{RT-PCR}

Total RNA of cultured neurons was prepared by using the Trizol Reagent (Invitrogen, USA). The Superscript TM-III kit (Invitrogen, USA) was used for reverse-transcribed with oligo $\mathrm{dT}$ and $2.5 \mathrm{mg}$ total RNA. Primer sequences were as follows: NM_019266 (SCN8A), and NM_031144 ( $\beta$-actin). SCN8A forward 5'-CTG GAG AAT GGA GGC ACA CAC-3', reverse 5' ACG CTG CTG CTT CTC CTT GTC- $3^{\prime}$; and $\beta$-actin forward 5'-CGT TGA CAT CCG TAA AGA CCT-3', reverse 5' ${ }^{\prime}$-TCA GGA GGA GCA ATG ATC TTG-3'. The resulting cDNA PCR amplification was performed by using the following protocol: $95^{\circ} \mathrm{C}$ for $10 \mathrm{~s}$ followed by 50 cycles of $95^{\circ} \mathrm{C}$ for $5 \mathrm{~s}$ and $60^{\circ} \mathrm{C}$ for $31 \mathrm{~s}$, and verified by $2.0 \%$ agarose gel electrophoresis. Images were captured by using Gel Imaging System (Bio-Rad). The amplicon size of each gene was 108 and $144 \mathrm{bp}$, respectively.

\section{Immunofluorescence Staining and Immunohistochemistry}

Cells were fixed with $4 \%$ paraformaldehyde for $20 \mathrm{~min}$, permeabilized with $0.1 \%$ Triton-x-100 for $5 \mathrm{~min}$, and incubated with $5 \%$ BSA for $60 \mathrm{~min}$ at room temperature to block non-specific binding. Without washing, the diluted primary antibodies (MAP2, Abcam-ab32454; Nav1.6, Abcam-ab65166) were added and incubated at $4^{\circ} \mathrm{C}$ overnight. After three washes with PBS, cells were incubated with the corresponding secondary antibodies at room temperature for $1 \mathrm{~h}$. For immunohistochemistry, cells were stained with DAB kit (Vector Laboratories) according to the instructions of the manufacturer for peroxidase labeling. Images were acquired from a fluorescence microscopy (Leica Microsystems DM400B, Germany).

\section{Image Analysis and Quantification}

Quantitative analysis of mean fluorescence intensities (MFIs) of immunoreactive neurons was performed using Image J software (National Institutes of Health). MFI per square micrometer was calculated by dividing the MFI units by the area of outlined regions.

\section{RESULTS}

\section{Elevated Excitability in APP/PS1 Mice}

To investigate change in intrinsic excitability in APP/PS1 mice, whole-cell patch-clamp recordings were performed on $12 \mathrm{DIV}$ (days in vitro) primary cultured neurons obtained from P0 APP/PS1 mice and littermate wide type mice in current-clamp mode. Frequency, threshold, and peak amplitude of action potentials (AP) were examined by different protocols. AP firing frequencies (f) elicited by increasing depolarizing currents $(200 \mathrm{pA}, 500 \mathrm{~ms})$ were significantly increased in neurons from $\mathrm{APP} / \mathrm{PS} 1$ mice compared to WT mice (Figures 1A,D; $\mathrm{f}_{\mathrm{WT}}=$ $15.375 \pm 3.428 \mathrm{~Hz}, n=12 ; \mathrm{f}_{\mathrm{APP} / \mathrm{PS} 1}=23.25 \pm 7.264 \mathrm{~Hz}, n=10$; $p=0.0128)$. We used a depolarizing current ( $80 \mathrm{pA}, 10 \mathrm{~ms})$ to induce a single firing of an AP. Threshold potential ( $\left.\mathrm{V}_{\text {threshold }}\right)$ and amplitude of action potential $\left(\mathrm{V}_{\text {peak }}\right)$ were recorded and compared with WT. We found that thresholds of neurons from APP/PS1 mice were significantly decreased compared to WT mice (Figures 1B,E; $\mathrm{V}_{\text {threshold, } \mathrm{WT}}=-29.001 \pm 2.304 \mathrm{mV}, n=$ 9; $\left.\mathrm{V}_{\text {threshold, APP/PS1 }}=-41.601 \pm 1.965 \mathrm{mV}, n=9 ; p=0.0012\right)$, but the peak amplitude was not (Figures 1C,F; $\mathrm{V}_{\text {peak, WT }}=$ $46.159 \pm 2.663 \mathrm{mV}, n=9 ; \mathrm{V}_{\text {peak, }} \mathrm{APP} / \mathrm{PS} 1=47.236 \pm 3.849 \mathrm{mV}$, $n=9 ; p=0.6475)$. These results suggested that the excitability of mature neurons obtained from APP/PS1 mice was increased.

\section{$A \beta_{1-42}$ Increases Excitability in Cultured Cortical Neurons from Mice}

It is likely that diverse factors contribute to the pathogenesis of $\mathrm{AD}$ patients or mice (Blennow et al., 2006; Bertram and Tanzi, 2008; Mucke, 2009). Among them, A $\beta$ stands out on the basis of overwhelming genetic evidence and strong experimental 


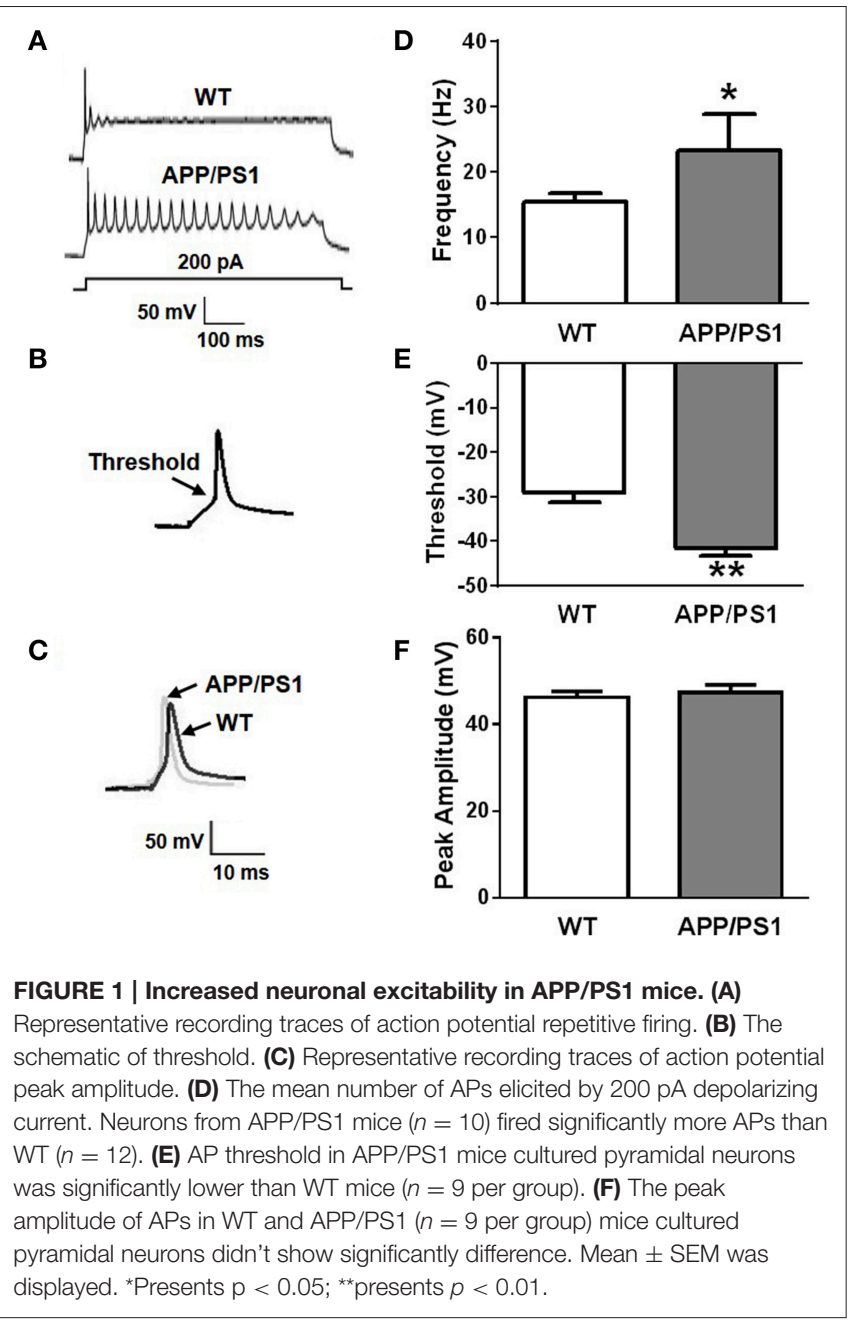

data (Farrer et al., 1997; Hardy and Selkoe, 2002; Tanzi and Bertram, 2005; Mahley and Huang, 2006). Accordingly, we attempted to investigate whether $A \beta_{1-42}$ contributed to intrinsic excitability. Cell viability was firstly determined by MTT assay in primary cultured neurons treated with $5 \mu \mathrm{M} \mathrm{A} \beta_{42-1}$ or $5 \mu \mathrm{M}$ $A \beta_{1-42}$ for $24 \mathrm{~h}$. We found that $A \beta_{1-42}$ slightly induced loss of neuron viability (Supplementary Figure S2; $n=3$, means three independent experiments; $p=0.047$ ). As described previously, whole-cell patch-clamp recordings were performed in current-clamp mode on normal morphological primary neurons which were incubated with $A \beta_{1-42}$ or $A \beta_{42-1}$ for $24 \mathrm{~h}$. Frequency, threshold, and peak amplitude of AP were examined. We found AP firing frequencies were significantly increased in neurons after treatment with $\mathrm{A} \beta_{1-42}$ peptide compared to controls (Figures 2A,D; $f_{\text {control }}=20.25 \pm$ $4.742 \mathrm{~Hz}, n=8, p=0.0050 ; \mathrm{f}_{\mathrm{A} \beta 42-1}=20.75 \pm 4.644 \mathrm{~Hz}$, $\left.n=8, p=0.0054 ; \mathrm{f}_{\mathrm{A} \beta 1-42}=43.25 \pm 5.028 \mathrm{~Hz}, n=8\right)$. $\mathrm{A} \beta_{1-42}$ also significantly decreased the threshold (Figures 2B,E; $\mathrm{V}_{\text {threshold, control }}=-33.83 \pm 1.207 \mathrm{mV}, n=7, p=0.0126$; $\mathrm{V}_{\text {threshold, } \mathrm{A} \beta 42-1}=-32.55 \pm 0.6600 \mathrm{mV}, n=7, p=0.0035$; $\left.\mathrm{V}_{\text {threshold, } \mathrm{A} \beta 1-42}=-41.37 \pm 1.771 \mathrm{mV}, n=7\right)$. But it had no effect on the peak amplitude (Figures 2C,F; $\mathrm{V}_{\text {peak, control }}=42.83$
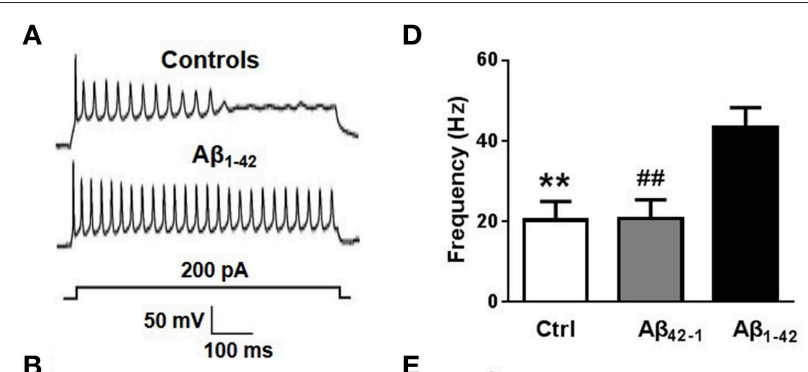

B

E

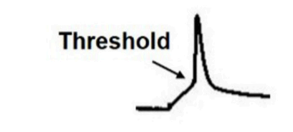

C

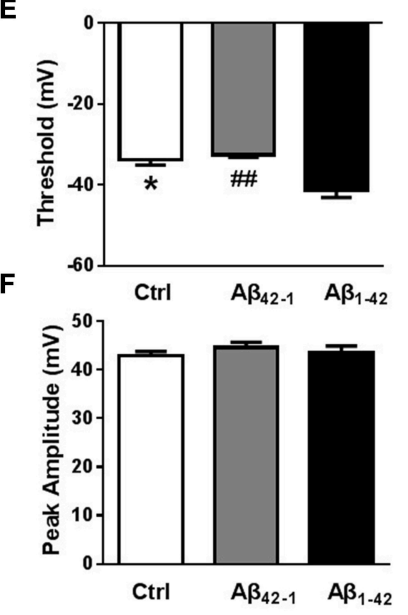

FIGURE 2 | A $\beta$ affects neuronal excitability. (A) Representative recording traces of action potential repetitive firing. (B) The schematic of threshold. (C) Representative recording traces of action potential peak amplitude. (D) The mean number of APs elicited by 200 pA depolarizing current. Neurons after $\mathrm{A} \beta_{1-42}$ treatment $(n=8)$ fired significantly more APs than controls (both negative control group and reverse peptide $A \beta_{42-1}$ group, $n=8$ ). (E) AP threshold in pyramidal neurons treated with $A \beta_{1-42}(n=7)$ was significantly lower than controls $(n=7)$. (F) The peak amplitude of APs in pyramidal neurons treated with $A \beta_{1-42}(n=7)$ didn't show significantly difference with controls $(n=7)$. Mean \pm SEM was displayed. *Presents $p<0.05$ vs. control group; ** presents $p<0.01$ vs. control group; \#\# presents $p<0.01$ vs. $\mathrm{A} \beta_{1-42}$ group.

$\pm 0.9437 \mathrm{mV}, n=7, p=0.6579 ; \mathrm{V}_{\text {peak, } \mathrm{A} \beta 42-1}=44.60 \pm$ $1.051 \mathrm{mV}, n=7, p=0.5633 ; \mathrm{V}_{\text {peak, } \mathrm{A} \beta 1-42}=43.58 \pm 1.305 \mathrm{mV}$, $n=7)$. These results suggested that incubation in $\mathrm{A} \beta_{1-42}$ increases neuronal excitability in vitro.

\section{Increased Neuronal Excitability Induced by $A \beta_{1-42}$ Due to an Up-Regulation of Nav Current}

In mammalian neurons, dense clusters of voltage-gated sodium channels (Nav) at the axonal initial segment and nodes of Ranvier underlie action potential generation and fast propagation (Leterrier et al., 2011). In addition, non-inactivating persistent sodium currents support maintained depolarization during and between action potentials. Finally, the resurgent persistent sodium current is triggered upon repolarization and supports repetitive firing in some types of neurons (Raman et al., 1997). We therefore hypothesized that the increased excitability induced by $A \beta_{1-42}$ could be due, at least in part, to an upregulation of Nav current. To test this hypothesis, we evaluated the magnitude 
of Nav currents in voltage-clamp mode after incubation with $\mathrm{A} \beta_{1-42}$ or reverse peptide for $24 \mathrm{~h}$. Representative traces of the total inward current recorded in response to voltage steps from -60 to $+60 \mathrm{mV}$ are shown in Figure 3A. Current density curves (Figure 3B) and peak current densities (Figure 3C) were significantly increased after $A \beta_{1-42}$ treatment compared to controls $\left(\right.$ Peak $_{\text {control }}=79.18 \pm 11.60 \mathrm{pA} / \mathrm{pF}, n=12, p=0.0028$; Peak $_{\mathrm{A} \beta 42-1}=74.14 \pm 13.54 \mathrm{pA} / \mathrm{pF}, n=12, p=0.0031$; Peak $_{\mathrm{A} \beta 1-42}=146.3 \pm 10.70 \mathrm{pA} / \mathrm{pF}, n=12$ ).

We next investigated the effect of $A \beta_{1-42}$ on sodium channel kinetic characteristics (Figures 3D,E). We found that $A \beta_{1-42}$ did not significantly shift the voltage-dependent sodium activation curve (Figure 3D). Single Boltzmann distribution fits showed a $\mathrm{V}_{1 / 2 \text {, control }}=-41.62 \pm 1.462 \mathrm{mV}$, and a $\kappa$ of $4.165 \pm 1.548 \mathrm{mV}$ $(n=12) ; \mathrm{a} \mathrm{V}_{1 / 2, \mathrm{~A} \beta 42-1}=-41.71 \pm 1.768 \mathrm{mV}$ and $\mathrm{a} \kappa$ of $4.795 \pm 1.825 \mathrm{mV}(n=12)$; and $\mathrm{a} \mathrm{V}_{1 / 2, \mathrm{~A} \beta 1-42}=-41.19$ $\pm 1.052 \mathrm{mV}$ and $\mathrm{a} \kappa$ of $4.155 \pm 1.184 \mathrm{mV}(n=12)$. For steady-state inactivation curves (Figure $3 \mathbf{E}$ ), the $\mathrm{V}_{1 / 2}$ and $\kappa$ of inactivation also did not change significantly $\left(\mathrm{V}_{1 / 2}\right.$, control $=$ $-51.47 \pm 1.040 \mathrm{mV}$ and $\kappa=6.992 \pm 1.017 \mathrm{mV}, n=12$; $\mathrm{V}_{1 / 2, \mathrm{~A} 42-1}=-51.90 \pm 0.8201 \mathrm{mV}$ and $\kappa=8.384 \pm 0.8552 \mathrm{mV}$, $n=12 ; \mathrm{V}_{1 / 2, \mathrm{~A} \beta 1-42}=-51.40 \pm 0.4131 \mathrm{mV}$ and $\kappa=7.723 \pm$ $0.4178 \mathrm{mV}, n=12)$.
Overall, these results demonstrated that exposure of neurons to $A \beta_{1-42}$ leads to an increased neuronal excitability, likely through a Nav current-mediated mechanism.

\section{Increased Expression of Nav in Cultured Neurons and APP/PS1 Mice}

Although, the experiments described above revealed that $A \beta_{1-42}$ increased neuronal excitability, perhaps dues to increasing Nav currents, it remained unclear how the Nav currents increased. There was no observable difference in sodium channel kinetic characteristics after $A \beta_{1-42}$ incubation (Figures 3D,E). We then examined the expression of $\mathrm{Nav}$ in neurons after $\mathrm{A} \beta_{1-42}$ treatment. Using Western blot analysis of cultured cortical neurons, we found that incubation with $A \beta_{1-42}$ significantly increased the expression of $\mathrm{Nav}$ [Figures 4A,B; $n=3$;

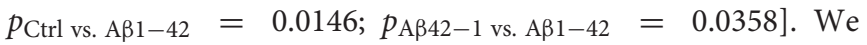
also investigated the Nav1.6 subtype, which plays a major role in the transmission of subthreshold currents, namely the persistent and resurgent currents (Raman et al., 1997), and the electrophysiological properties of Nav1.6 make these channels especially suited for the sustained repetitive firing of neurons (Van Wart and Matthews, 2006). As shown in Figures 4C,D, Nav1.6 displayed a significant increase after $A \beta_{1-42}$ treatment
A

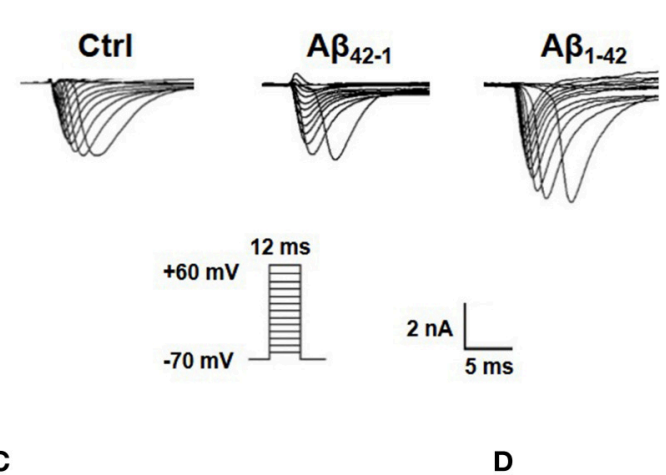

B

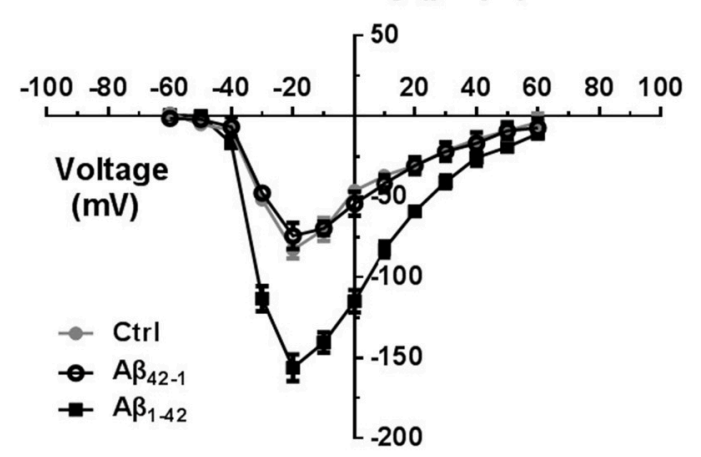

$\mathbf{E}$
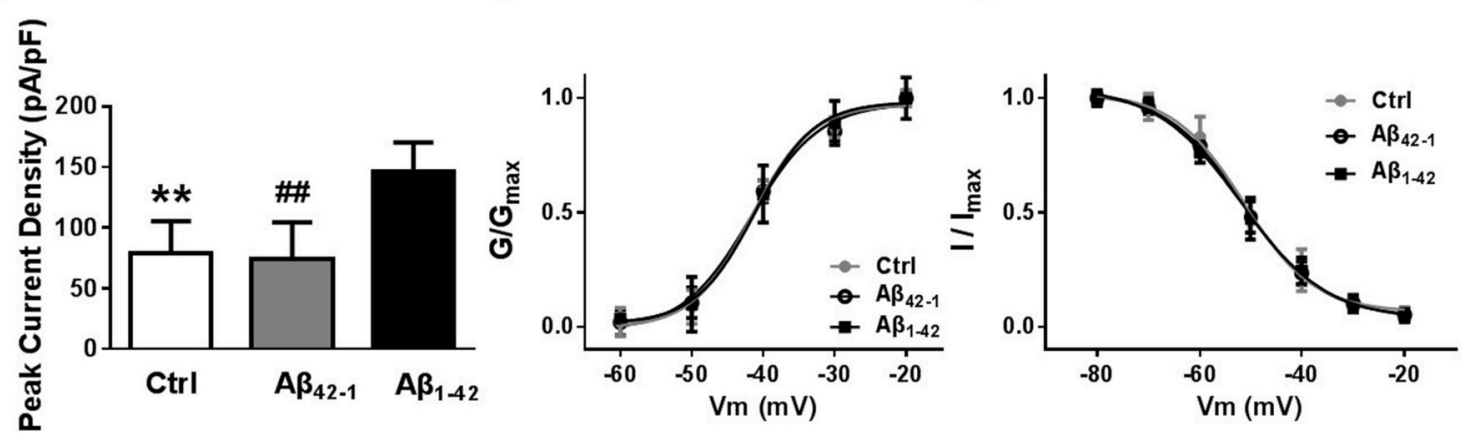

FIGURE 3 | A $\beta_{1-42}$ up-regulates voltage-dependent sodium current. (A) Representative traces of voltage gated sodium currents recorded in response to voltage steps from -60 to $+60 \mathrm{mV}$. (B) Current density-voltage relationship, illustrates that $\mathrm{Na}^{+}$current density recorded from $\mathrm{A} \beta_{1-42}$ treatment pyramidal neurons was significantly bigger than counterparts (negative control group and reverse peptide $A \beta_{42--1}$ group, $n=12$ ). (C) Graph, data showed peak current density recorded from $A \beta_{1-42}$ treatment neurons was significantly bigger than counterparts $(n=12)$. (D) Normalized steady-state activation curves for $\mathrm{Na}^{+}$currents recorded from cultured pyramidal neurons after $A \beta_{1-42}$ treatment and counterparts $(n=12)$. The activation curves were not significantly shift after $A \beta_{1-42}$ treatment. $(E)$ Normalized steady-state inactivation curves for $\mathrm{Na}^{+}$currents recorded from these three groups, and the inactivation curve was not significantly shift after $\mathrm{A} \beta_{1}-42$

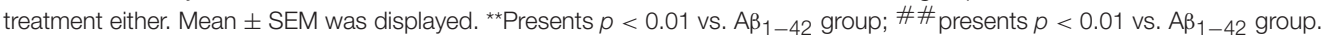


A

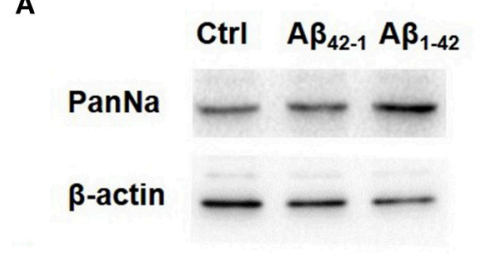

B

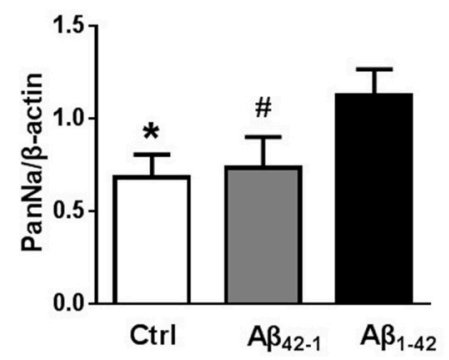

C

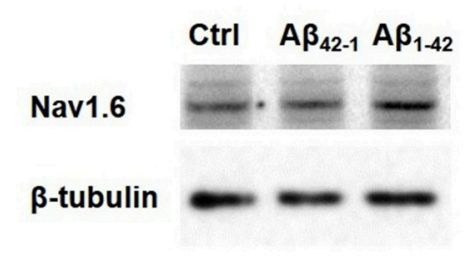

D

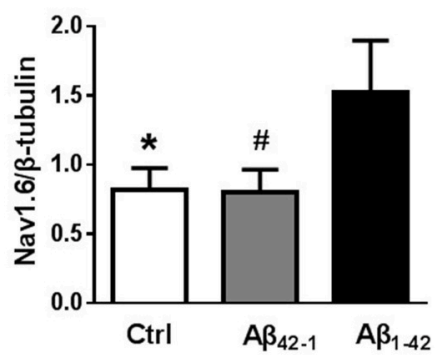

E

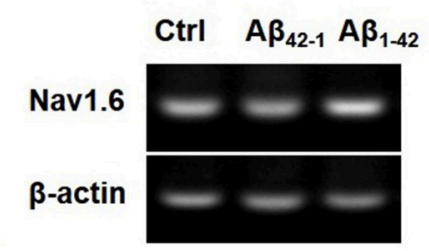

F

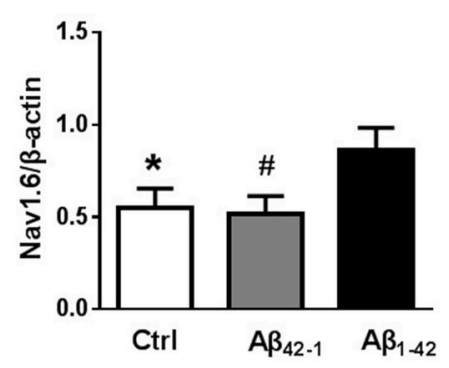

FIGURE 4 | A $\boldsymbol{\beta}_{\mathbf{1}-42}$ increases the expression of sodium channels. (A) Equal amounts of collected protein samples obtained from 12 DIV neurons after different treatments were analyzed by western blot to detect the protein expression level of sodium channel ( $n=3$ per group). (B) Quantification of protein levels of sodium channel. $\beta$-actin was used as an internal control ( $n=3$ per group). (C) Western blots of 12 DIV neurons after different treatments to detect the expression of Nav1.6 protein ( $n=3$ per group). (D) Quantification of protein levels of Nav1.6. $\beta$-tubulin was used as an internal control ( $n=3$ per group). (E) RT-PCR of Nav1.6 mRNA levels of 12 DIV neurons after different treatments ( $n=3$ per group). (F) Quantification of mRNA levels of Nav1.6. $\beta$-actin was used as an internal control ( $n=3$ per group). Mean \pm SEM was displayed. *Presents $p<0.05$ vs. A $\beta_{1-42}$ group; \#presents $p<0.05$ vs. A $\beta_{1-42}$ group.

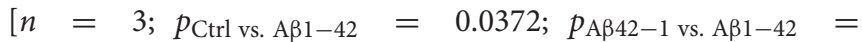
0.0354]. To further identify the increased expression of Nav1.6 after $\mathrm{A} \beta_{1-42}$ treatment, mRNA expression levels were detected too. Paralleled with western blot analysis, Nav1.6 mRNA obtained from cultured neurons treated with $\mathrm{A} \beta_{1-42}$ showed significantly increased than control groups [Figures 4E,F,

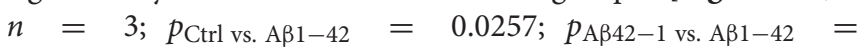
0.017].

Morphological methods were also used to test the expression of Nav1.6. The localization of Nav1.6 in neurons was revealed by immunohistochemistry (Figure 5A). Consistent with the result from western blotting, most neurons incubated with $A \beta_{1-42}$ showed significantly deepening stain [Figures 5A,C; $n=3$; $\left.p_{\text {Ctrl vs. } A \beta 1-42}=0.0162\right]$. After obtaining these results, we wondered if the expression of Nav1.6 in APP/PS1 mouse brains would have changed. Coronal brain sections from 9 month old APP/PS1 mice and WT littermates were stained for MAP2, a maker of mature neurons, and Nav1.6 (Figure 5B; $n=3$ ). We found, that APP/PS1 mice exhibited more Nav1.6 immunoreactivity than WT mice in cortex regions (Figure 5D; $n=3 ; p=0.0286$ ).

Taken together, our findings and previous studies suggest that $\mathrm{A} \beta_{1-42}$ increased the excitability of cultured cortical neurons, and this effect was mediated by overexpression of Nav, with the Nav1.6 subtype perhaps accounting for much of this increase.

\section{DISCUSSION}

In addition to cognitive deficits, $\mathrm{AD}$ patients have an increased incidence of epileptic seizures. This incidence is even higher in patients with early-onset AD who overexpress human APP, the proteolysis of which generates A $\beta$ (Palop and Mucke, 2009). Hyperexcitability is also detected in the brains of various $\mathrm{AD}$ transgenic mice (Tamagnini et al., 2015), including the APP/PS1 mice used here. Such aberrant increases in network excitability and compensatory inhibitory mechanisms in the hippocampus may contribute to the cognitive deficits in $\mathrm{AD}$ (Palop et al., 2007; Sanchez et al., 2012; Verret et al., 2012). However, the mechanisms underlying the hyperexcitability detected in $\mathrm{AD}$ brains are not fully understood.

In the present study, we investigated the excitability in cultured pyramidal neurons of APP/PS1 mice using patch clamp techniques. We found that the excitability of $12 \mathrm{DIV}$ cultured pyramidal neurons from APP/PS1 mice was significantly greater than in WT littermates. Additionally, AP firing frequencies increased and $V_{\text {threshold }}$ decreased in neurons from APP/PS1 mice compared to WT mice. These results confirm previous studies that showed neuronal hyperexcitability in APP/PS1 mice by patch clamp methods. In recent years, many studies demonstrated that $A \beta$ is associated with increased excitability of neurons in vitro and in animal models, leading to hypersynchronous network activity and higher risk for seizures (Minkeviciene et al., 2009; Busche et al., 2012; Born et al., 2014; Davis et al., 2014). In our current work, we observed the altered excitability of pyramidal neurons after treatment with $A \beta$. The higher firing frequency and lower threshold indicated an increased intrinsic excitability of pyramidal neurons.

$\mathrm{A} \beta$-induced aberrant excitatory activity might occur through many different mechanisms. Previous studies have shown that $\mathrm{A} \beta$ can downregulate A-type $\mathrm{K}^{+}$currents, thereby increasing excitability of hippocampal pyramidal neurons (Good and Murphy, 1996; Chen, 2005). Elevated A $\beta$ also causes GABAergic 
A

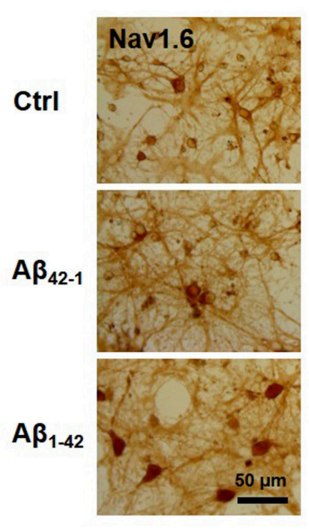

C

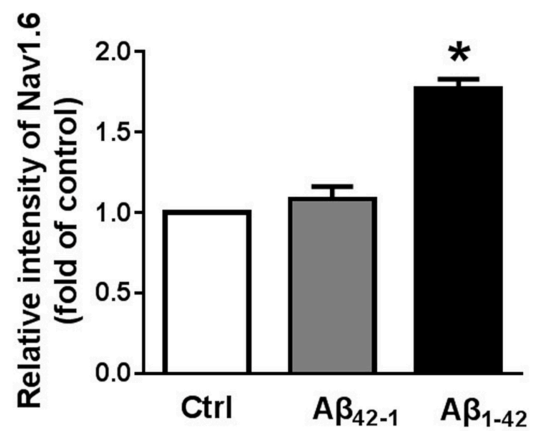

B
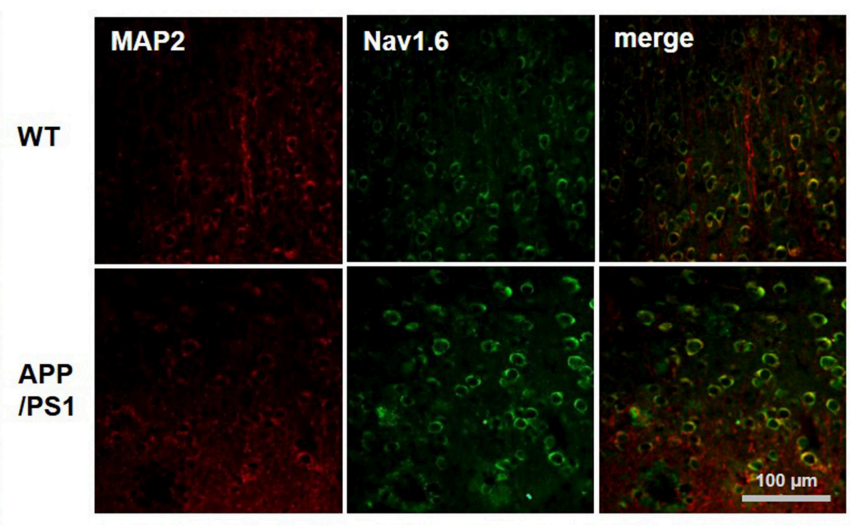

D

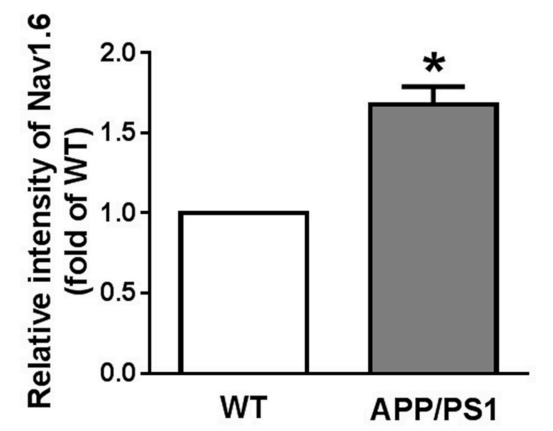

FIGURE 5 | Elevated expression of Nav1.6 in cultured neurons and APP/PS1 mice. (A) Immunohistochemistry images of 12 DIV primary cortical culture neurons after $24 \mathrm{~h} \mathrm{~A} \beta_{42-1}$ or $\mathrm{A} \beta_{1-42}$ treatments stained with anti-Nav1.6 antibody. Scale bar $=50 \mu \mathrm{m}$ ( $n=3$ per group). (B) Immunostaining images of temporal lobe cortex sections obtained from 9 months APP/PS1 mice and its littermates co-stained with anti-Nav1.6 antibody and anti-MAP2 antibody ( $n=3$ per group). (C) Quantification of Nav1.6 immunohistochemistry images by using intensity analysis ( $n=3$ per group). (D) Quantification of fluorescence intensity of Nav1.6 ( $n=3$ per group). Mean \pm SEM was displayed. *Presents $p<0.05$ vs. control group.

dysfunction and attenuates excitatory synaptic transmission by decreasing the number of surface AMPA and NMDA receptors (Kamenetz et al., 2003; Hsieh et al., 2006; Shankar et al., 2007), as well as disrupting the development of aberrant synchrony in neural networks, damaging cognitive functions. Subsequent studies proved that neuronal activity regulates $A \beta$ production (Kamenetz et al., 2003; Cirrito et al., 2005). Blocking neuronal electrical activity with TTX, a sodium channel blocker, decreased the cleavage of APP by $\beta$-secretase (Kamenetz et al., 2003). Recent studies found that blocking the network hyperactivity with the anti-epileptic drug lamotrigine, a voltage-dependent sodium channel inhibitor, reversed synaptic disorder and cognitive dysfunction in APP transgenic mice (Bakker et al., 2012; Sanchez et al., 2012; Zhang et al., 2014). These results indicate that $A \beta$, or other AD-related factors, plays a significant role in regulating neuronal activity at specific types of neurons as well as in wider neuronal networks, and $\mathrm{A} \beta$ and sodium channels have a certain relationship.

Voltage-dependent sodium currents play a critical role in action potential depolarization and firing frequency in many types of neurons (Kim et al., 2005; Baroni et al., 2013). We therefore hypothesized that the increased excitability induced by $A \beta_{1-42}$ could be due, at least in part, to an upregulation of the Nav current. As we expected, the peaks of the voltagedependent sodium current were significantly increased after $\mathrm{A} \beta_{1-42}$ treatment. The increased voltage-dependent sodium current could decrease action potential threshold and increase the probability of action potential generation in response to synaptic excitation, thus increasing the excitability of the neuron. However, $A \beta$ upregulated sodium currents without significantly altering the voltage-dependence of activation and inactivation. We found that $A \beta$ increased the expression of Nav and Nav1.6 in cultured neurons, indicating that the number of Nav channels could be altered by $A \beta_{1-42}$. These results provide a possible mechanism for the increased excitability of pyramidal neurons previously observed after $A \beta$ treatment. Confirming the causal relationship between the aberrant excitatory activity induced by $\mathrm{A} \beta$ and cognitive decline in $\mathrm{AD}$ patients would be an important insight into the pathogenesis of $\mathrm{AD}$ and provide new therapeutic avenues. 


\section{AUTHOR CONTRIBUTIONS}

Conceived and designed the experiments: XW, SL. Performed the experiments: XW, XZ, and CJ. Analyzed the data: XW, XZ, ZX, and QM. Contributed reagents/materials/analysis tools: TZ, NL. Wrote the paper: XW, XZ.

\section{ACKNOWLEDGMENTS}

This work was supported by Grant (81571061, 81371223, and 30871006) from the National Natural Science Foundation of China and the Research Fund for the Doctoral Program of Higher Education of China (201221051 10010).

\section{REFERENCES}

Bakker, A., Krauss, G. L., Albert, M. S., Speck, C. L., Jones, L. R., Stark, C. E., et al. (2012). Reduction of hippocampal hyperactivity improves cognition in amnestic mild cognitive impairment. Neuron 74, 467-474. doi: 10.1016/j.neuron.2012.03.023

Baroni, D., Barbieri, R., Picco, C., and Moran, O. (2013). Functional modulation of voltage-dependent sodium channel expression by wild type and mutated C121W-betal subunit. J. Bioenerg. Biomembr. 45, 353-368. doi: 10.1007/s10863-013-9510-3

Bertram, L., and Tanzi, R. E. (2008). Thirty years of Alzheimer's disease genetics: the implications of systematic meta-analyses. Nat. Rev. Neurosci. 9, 768-778. doi: $10.1038 / \mathrm{nrn} 2494$

Blennow, K., de Leon, M. J., and Zetterberg, H. (2006). Alzheimer's disease. Lancet 368, 387-403. doi: 10.1016/S0140-6736(06)69113-7

Born, H. A., Kim, J. Y., Savjani, R. R., Das, P., Dabaghian, Y. A., Guo, Q., et al. (2014). Genetic suppression of transgenic APP rescues Hypersynchronous network activity in a mouse model of Alzeimers disease. J. Neurosci. 34, 3826-3840. doi: 10.1523/JNEUROSCI.5171-13.2014

Brorson, J. R., Bindokas, V. P., Iwama, T., Marcuccilli, C. J., Chisholm, J. C., and Miller, R. J. (1995). The Ca2+ influx induced by beta-amyloid peptide 25-35 in cultured hippocampal neurons results from network excitation. J. Neurobiol. 26, 325-338. doi: 10.1002/neu.480260305

Busche, M. A., Chen, X., Henning, H. A., Reichwald, J., Staufenbiel, M., Sakmann, B., et al. (2012). Critical role of soluble amyloid-beta for early hippocampal hyperactivity in a mouse model of Alzheimer's disease. Proc. Natl. Acad. Sci. U.S.A. 109, 8740-8745. doi: 10.1073/pnas.1206171109

Catterall, W. A., Goldin, A. L., and Waxman, S. G. (2005). International Union of Pharmacology. XLVII. Nomenclature and structure-function relationships of voltage-gated sodium channels. Pharmacol. Rev. 57, 397-409. doi: $10.1124 / \mathrm{pr} .57 .4 .4$

Chen, C. (2005). beta-Amyloid increases dendritic Ca2+ influx by inhibiting the A-type $\mathrm{K}+$ current in hippocampal CA1 pyramidal neurons. Biochem. Biophys. Res. Commun. 338, 1913-1919. doi: 10.1016/j.bbrc.2005.10.169

Choi, D. W. (1988). Glutamate neurotoxicity and diseases of the nervous system. Neuron 1, 623-634. doi: 10.1016/0896-6273(88) 90162-6

Cirrito, J. R., Yamada, K. A., Finn, M. B., Sloviter, R. S., Bales, K. R., May, P. C., et al. (2005). Synaptic activity regulates interstitial fluid amyloid-beta levels in vivo. Neuron 48, 913-922. doi: 10.1016/j.neuron.2005.10.028

Davis, K. E., Fox, S., and Gigg, J. (2014). Increased hippocampal excitability in the 3xTgAD mouse model for Alzheimer's disease in vivo. PLoS ONE 9:e91203. doi: 10.1371/journal.pone.0091203

Farrer, L. A., Cupples, L. A., Haines, J. L., Hyman, B., Kukull, W. A., Mayeux, R., et al. (1997). Effects of age, sex, and ethnicity on the association between apolipoprotein E genotype and Alzheimer disease. A meta-analysis. APOE and Alzheimer disease meta analysis consortium. JAMA 278, 1349-1356. doi: 10.1001/jama.1997.03550160069041

\section{SUPPLEMENTARY MATERIAL}

The Supplementary Material for this article can be found online at: http://journal.frontiersin.org/article/10.3389/fnins. 2016.00094

Supplementary Figure $\mathbf{S} 1$ | Biochemical characterization of $\mathbf{A} \beta_{1-42}$. Eighty nanogram aged $A \beta_{1-42}$ and $A \beta_{1-42}$ monomer samples were analyzed by SDS-PAGE and detected with anti-6E10 antibody. After $48 \mathrm{~h}$ aggregated $A \beta_{1-42}$ with different molecular weight forms were displayed. aged presents $A \beta_{1-42}$ with aggregation treatment; mono presents $A \beta_{1-42}$ monomer.

Supplementary Figure $\mathbf{S} 2$ | Cell viability measurement of neuron treated with $\mathbf{A} \boldsymbol{\beta}_{\mathbf{1}} \mathbf{4 2}$. Cell viability was determined by MTT assay in primary cultured neurons treated with $5 \mu \mathrm{MA} \beta_{42-1}$ or $5 \mu \mathrm{MA} \beta_{1-42}$ for $24 \mathrm{~h}$. $A \beta_{1-42}$ induced slightly loss of cell viability in neurons. ( $n=3$, means 3 independent experiments). Mean \pm SEM was displayed. MTT, 3-(4,5-dimethylthiazol-2-yl)-2,

5-diphenyltetrazolium bromide. *Presents $p<0.05$ vs. control group.

Goldin, A. L., Barchi, R. L., Caldwell, J. H., Hofmann, F., Howe, J. R., Hunter, J. C., et al. (2000). Nomenclature of voltage-gated sodium channels. Neuron 28, 365-368. doi: 10.1016/S0896-6273(00)00116-1

Good, T. A., and Murphy, R. M. (1996). Effect of beta-amyloid block of the fast-inactivating $\mathrm{K}+$ channel on intracellular $\mathrm{Ca} 2+$ and excitability in a modeled neuron. Proc. Natl. Acad. Sci. U.S.A. 93, 15130-15135. doi: 10.1073/pnas.93.26.15130

Hardy, J., and Selkoe, D. J. (2002). The amyloid hypothesis of Alzheimer's disease: progress and problems on the road to therapeutics. Science 297, 353-356. doi: 10.1126/science. 1072994

Hsieh, H., Boehm, J., Sato, C., Iwatsubo, T., Tomita, T., Sisodia, S., et al. (2006). AMPAR removal underlies Abeta-induced synaptic depression and dendritic spine loss. Neuron 52, 831-843. doi: 10.1016/j.neuron.2006.10.035

Jones, R. S., Minogue, A. M., Connor, T. J., and Lynch, M. A. (2013). Amyloidbeta-induced astrocytic phagocytosis is mediated by CD36, CD47 and RAGE. J. Neuroimmune Pharmacol. 8, 301-311. doi: 10.1007/s11481-012-9427-3

Kamenetz, F., Tomita, T., Hsieh, H., Seabrook, G., Borchelt, D., Iwatsubo, T., et al. (2003). APP processing and synaptic function. Neuron 37, 925-937. doi: 10.1016/S0896-6273(03)00124-7

Kim, D. Y., Ingano, L. A., Carey, B. W., Pettingell, W. H., and Kovacs, D. M. (2005). Presenilin/gamma-secretase-mediated cleavage of the voltage-gated sodium channel beta2-subunit regulates cell adhesion and migration. J. Biol. Chem. 280, 23251-23261. doi: 10.1074/jbc.M412938200

Leterrier, C., Brachet, A., Dargent, B., and Vacher, H. (2011). Determinants of voltage-gated sodium channel clustering in neurons. Semin. Cell Dev. Biol. 22, 171-177. doi: 10.1016/j.semcdb.2010.09.014

Liu, C., Tan, F. C., Xiao, Z. C., and Dawe, G. S. (2015). Amyloid precursor protein enhances Nav1.6 sodium channel cell surface expression. J. Biol. Chem. 290, 12048-12057. doi: 10.1074/jbc.M114.617092

Mahley, R. W., and Huang, Y. (2006). Apolipoprotein (apo) E4 and Alzheimer's disease: unique conformational and biophysical properties of apoE4 can modulate neuropathology. Acta Neurol. Scand. Suppl. 185, 8-14. doi: 10.1111/j.1600-0404.2006.00679.x

Minkeviciene, R., Rheims, S., Dobszay, M. B., Zilberter, M., Hartikainen, J., Fulop, L., et al. (2009). Amyloid beta-induced neuronal hyperexcitability triggers progressive epilepsy. J. Neurosci. 29, 3453-3462. doi: 10.1523/JNEUROSCI.5215-08.2009

Mucke, L. (2009). Neuroscience: Alzheimer's disease. Nature 461, 895-897. doi: $10.1038 / 461895 a$

Ogiwara, I., Miyamoto, H., Morita, N., Atapour, N., Mazaki, E., Inoue, I., et al. (2007). Nav1.1 localizes to axons of parvalbumin-positive inhibitory interneurons: a circuit basis for epileptic seizures in mice carrying an Scnla gene mutation. J. Neurosci. 27, 5903-5914. doi: 10.1523/JNEUROSCI.527006.2007

Olney, J. W., Wozniak, D. F., and Farber, N. B. (1997). Excitotoxic neurodegeneration in Alzheimer disease. New hypothesis and new therapeutic strategies. Arch. Neurol. 54, 1234-1240. doi: 10.1001/archneur.1997.00550220042012 
Ong, W. Y., Tanaka, K., Dawe, G. S., Ittner, L. M., and Farooqui, A. A. (2013). Slow excitotoxicity in Alzheimer's disease. J. Alzheimers. Dis. 35, 643-668. doi: 10.3233/JAD-121990

Palop, J. J., Chin, J., Roberson, E. D., Wang, J., Thwin, M. T., Bien-Ly, N., et al. (2007). Aberrant excitatory neuronal activity and compensatory remodeling of inhibitory hippocampal circuits in mouse models of Alzheimer's disease. Neuron 55, 697-711. doi: 10.1016/j.neuron.2007.07.025

Palop, J. J., and Mucke, L. (2009). Epilepsy and cognitive impairments in Alzheimer's disease. Arch. Neurol. 66, 435-440. doi: 10.1001/archneurol.2009.15

Palop, J. J., and Mucke, L. (2010). Amyloid-beta-induced neuronal dysfunction in Alzheimer's disease: from synapses toward neural networks. Nat. Neurosci. 13, 812-818. doi: 10.1038/nn.2583

Putcha, D., Brickhouse, M., O’Keefe, K., Sullivan, C., Rentz, D., Marshall, G., et al. (2011). Hippocampal hyperactivation associated with cortical thinning in Alzheimer's disease signature regions in non-demented elderly adults. J. Neurosci. 31, 17680-17688. doi: 10.1523/JNEUROSCI.474011.2011

Ragsdale, D. S. (2008). How do mutant Nav1.1 sodium channels cause epilepsy? Brain Res. Rev. 58, 149-159. doi: 10.1016/j.brainresrev.2008.01.003

Raman, I. M., Sprunger, L. K., Meisler, M. H., and Bean, B. P. (1997). Altered subthreshold sodium currents and disrupted firing patterns in Purkinje neurons of Scn8a mutant mice. Neuron 19, 881-891. doi: 10.1016/S08966273(00)80969-1

Sanchez, P. E., Zhu, L., Verret, L., Vossel, K. A., Orr, A. G., Cirrito, J. R., et al. (2012). Levetiracetam suppresses neuronal network dysfunction and reverses synaptic and cognitive deficits in an Alzheimer's disease model. Proc. Natl. Acad. Sci. U.S.A. 109, E2895-E2903. doi: 10.1073/pnas. 1121081109

Shankar, G. M., Bloodgood, B. L., Townsend, M., Walsh, D. M., Selkoe, D. J., and Sabatini, B. L. (2007). Natural oligomers of the Alzheimer amyloidbeta protein induce reversible synapse loss by modulating an NMDA-type glutamate receptor-dependent signaling pathway. J. Neurosci. 27, 2866-2875. doi: 10.1523/JNEUROSCI.4970-06.2007

Tamagnini, F., Scullion, S., Brown, J. T., and Randall, A. D. (2015). Intrinsic excitability changes induced by acute treatment of hippocampal CA1 pyramidal neurons with exogenous amyloid beta peptide. Hippocampus 25, 786-797. doi: 10.1002/hipo. 22403
Tanzi, R. E., and Bertram, L. (2005). Twenty years of the Alzheimer's disease amyloid hypothesis: a genetic perspective. Cell 120, 545-555. doi: 10.1016/j.cell.2005.02.008

Trimmer, J. S., and Rhodes, K. J. (2004). Localization of voltage-gated ion channels in mammalian brain. Annu. Rev. Physiol. 66, 477-519. doi: 10.1146/annurev.physiol.66.032102.113328

Van Wart, A., and Matthews, G. (2006). Impaired firing and cell-specific compensation in neurons lacking nav1.6 sodium channels. J. Neurosci. 26, 7172-7180. doi: 10.1523/JNEUROSCI.1101-06.2006

Verret, L., Mann, E. O., Hang, G. B., Barth, A. M., Cobos, I., Ho, K., et al. (2012). Inhibitory interneuron deficit links altered network activity and cognitive dysfunction in Alzheimer model. Cell 149, 708-721. doi: 10.1016/j.cell.2012.02.046

Xu, D. E., Zhang, W. M., Yang, Z. Z., Zhu, H. M., Yan, K., Li, S., et al. (2014). Amyloid precursor protein at node of Ranvier modulates nodal formation. Cell Adh. Migr. 8, 396-403. doi: 10.4161/cam.28802

Yu, F. H., and Catterall, W. A. (2003). Overview of the voltage-gated sodium channel family. Genome Biol. 4:207. doi: 10.1186/gb-2003-4-3-207

Yu, F. H., Mantegazza, M., Westenbroek, R. E., Robbins, C. A., Kalume, F., Burton, K. A., et al. (2006). Reduced sodium current in GABAergic interneurons in a mouse model of severe myoclonic epilepsy in infancy. Nat. Neurosci. 9, 1142-1149. doi: 10.1038/nn1754

Zhang, M. Y., Zheng, C. Y., Zou, M. M., Zhu, J. W., Zhang, Y., Wang, J., et al. (2014). Lamotrigine attenuates deficits in synaptic plasticity and accumulation of amyloid plaques in APP/PS1 transgenic mice. Neurobiol. Aging 35, 2713-2725. doi: 10.1016/j.neurobiolaging.2014.06.009

Conflict of Interest Statement: The authors declare that the research was conducted in the absence of any commercial or financial relationships that could be construed as a potential conflict of interest.

Copyright (C) 2016 Wang, Zhang, Zhou, Li, Jang, Xiao, Ma and Li. This is an openaccess article distributed under the terms of the Creative Commons Attribution License (CC BY). The use, distribution or reproduction in other forums is permitted provided the original author(s) or licensor are credited and that the original publication in this journal is cited, in accordance with accepted academic practice. No use, distribution or reproduction is permitted which does not comply with these terms. 